\title{
Zinc inhibits Bax and Bak activation and cytochrome $c$ release induced by chemical inducers of apoptosis but not by death-receptor-initiated pathways
}

\author{
N Ganju ${ }^{1}$ and A Eastman ${ }^{*, 1}$ \\ 1 Department of Pharmacology and Toxicology, Dartmouth Medical School, \\ Hanover, NH, USA \\ * Corresponding author: A Eastman, Department of Pharmacology and \\ Toxicology, Dartmouth Medical School, 7650 Remsen, Hanover, NH 03755, \\ USA. Tel: 603-650-1501; Fax: 603-650-1129; \\ E-mail: alan.eastman@Dartmouth.edu
}

Received 11.10.02; revised 20.1.03; accepted 29.1.03

Edited by D. Nicholson

\begin{abstract}
Zinc has been known for many years to inhibit apoptosis but the mechanism remains unclear. Originally thought to inhibit an apoptotic endonuclease, zinc has subsequently been shown to inhibit steps earlier in the pathway. Since many additional steps in apoptosis have now been defined, we have re-evaluated the steps inhibited by zinc. In response to activation of the chemical-mediated death pathway by anisomycin, $0.3 \mathrm{mM}$ zinc inhibited Bax and Bak activation, cytochrome $c$ release, and all of the subsequent steps in apoptosis. In the receptor-mediated death pathway initiated by Fas or tumor necrosis factor, $3 \mathrm{mM}$ zinc was required to inhibit apoptosis as judged by inhibition of caspase 3 activity and DNA digestion, but it failed to inhibit cytochrome $c$ release, activation of Bax and Bak, or upstream signaling events in this pathway. These results are consistent with zinc selectively inhibiting activation of $\mathrm{BH} 3-$ only proteins required in the chemical pathway but inhibiting downstream caspase activation in the death-receptor pathway.

Cell Death and Differentiation (2003) 10, 652-661. doi:10.1038/ sj.cdd. 4401234
\end{abstract}

Keywords: anisomycin; Bid; caspase; Fas; tumor necrosis factor

Abbreviations: $\mathrm{CHX}$, cycloheximide; ECL, Enhanced chemiluminescence; SDS, Sodium dodecylsulfate; TNF, Tumor necrosis factor.

\section{Introduction}

Caspases play a critical role in the regulation of both the receptor-mediated and drug-induced apoptotic pathways. In the Fas receptor-mediated pathway, the Fas ligand leads to recruitment of caspase 8 to the receptor, where it is cleaved and activated. ${ }^{1}$ Two death pathways can then occur. In one, caspase 8 directly cleaves downstream effector caspases such as caspase 3 , leading to DNA digestion and proteolysis of the cell. ${ }^{2}$ The second pathway is more indirect, requiring that caspase 8 cleave the proapoptotic Bcl-2 family member Bid. ${ }^{3}$ Truncated Bid (tBid) then translocates to the mitochondria and causes cytochrome $c$ release. ${ }^{3,4}$ Recent reports have shown that Bax or Bak, also proapoptotic members of the Bcl2 family, are required for tBid to mediate this apoptotic cascade. ${ }^{5,6}$ Release of cytochrome $c$ and/or Smac/Diablo culminates in the activation of downstream caspases and finally DNA digestion. ${ }^{7-9}$

In chemical-induced apoptosis, the upstream effectors are not as clearly understood, but the signals also impact on the $\mathrm{Bcl}-2$ family of proteins. The current model suggests that once the insult has been detected and the cell has made the decision to undergo apoptosis, Bax translocates from the cytosol to the mitochondria, where it oligomerizes. This activation of Bax occurs independently of Bid activation, ${ }^{10}$ and may involve some other BH3-only member of the Bcl-2 family. Following Bax activation, cytochrome $c$ is released and downstream caspases are activated. Another proapoptotic Bcl-2 family member, Bak, is constitutively present in mitochondria, but otherwise acts like Bax in that it oligomerizes in response to an apoptotic stimulus leading to cytochrome $c$ release. In this chemical-mediated pathway, caspase 8 and Bid may also be activated, but as a consequence of feedback from caspase $3 .^{2,10}$ This feedback indicates that caspase 8 and Bid do not play significant roles in chemical-induced apoptosis but are simply activated in response to other caspases after the critical step of cytochrome $c$ release.

Zinc is an inhibitor of apoptosis. It was originally shown to inhibit glucocorticoid-induced killing of mouse thymocytes at a concentration of $400 \mu \mathrm{M}^{11}$ Zinc concentrations of $200-$ $5000 \mu \mathrm{M}$ zinc have also been shown to inhibit p75NTR, TGF $\beta$, and Fas receptor-mediated apoptosis. ${ }^{12-14}$ Additionally, zinc inhibits apoptosis induced through the chemical pathway by etoposide, staurosporine, and microtubule disrupting drugs. ${ }^{15-18}$ These levels of zinc are unlikely to be attained physiologically; rather they are an experimental means to elevate intracellular zinc. Protection can be afforded at much lower zinc concentrations when zinc ionophores are used. ${ }^{19}$ In these cases, $25 \mu \mathrm{M}$ zinc can be adequate to protect cells. The physiological relevance of zinc to the regulation of apoptosis has been further demonstrated by the observation that decreased intracellular zinc concentrations may precede early indicators of apoptosis in HL60 cells, ${ }^{20}$ while zinc depletion in cells results in apoptosis. ${ }^{21,22}$

The mechanism by which zinc inhibits apoptosis is not clearly understood. It was originally thought to inhibit the endonuclease involved in apoptotic DNA digestion. ${ }^{23} \mathrm{How}$ ever, it was subsequently shown that this protection was more likely mediated at a step further upstream in the apoptotic 
pathway. This laboratory established that zinc inhibits apoptosis induced by both receptor- and chemical-mediated pathways and this appeared to occur upstream of the activation of caspase $3 .^{16}$ Reports also suggest that zinc increases protein kinase $\mathrm{C}$ activity, ${ }^{24}$ which may result in the protection of cells from apoptosis. Recently, zinc has also been shown to inhibit the production of cyclic AMP by direct binding to adenylate cyclases, ${ }^{25}$ providing another possible mechanism of cell protection. Since many additional steps in the apoptotic pathway have now been defined, we have reevaluated the step(s) inhibited by zinc.

In response to activation of the chemical-mediated death pathway, 0.3 mM zinc inhibited Bax and Bak oligomerization and all of the subsequent steps in apoptosis. In the receptormediated death pathway, $3 \mathrm{mM}$ zinc was required to inhibit apoptosis as judged by inhibition of caspase 3 activity and DNA digestion, but it failed to inhibit Bax and Bak oligomerization and upstream signaling events in this pathway. These results demonstrate that zinc inhibits the two pathways at different steps and accordingly may help to identify critical regulators of apoptosis.

\section{Results}

\section{Anisomycin-induced apoptosis is inhibited by low concentrations of zinc}

Anisomycin is a potent activator of the chemical pathway of apoptosis. Incubation of human ML-1 leukemia cells with $10 \mu \mathrm{g} / \mathrm{ml}$ anisomycin for $2 \mathrm{~h}$ resulted in greater than $90 \%$ Hoechst positive staining, indicative of chromatin condensation, and extensive DNA digestion as measured by agarose gel electrophoresis (Figure 1). Anisomycin treatment alone resulted in DNA digestion as measured by agarose gel electrophoresis (Figure 1). D4GDI cleavage, indicative of caspase 3 activation, also occurred in response to anisomycin. Bax translocated from the cytosolic to the pellet fraction of cells and cytochrome $c$ was released from the mitochondria (i.e., the pellet fraction) into the cytosol (Figure 1b). Caspase 8 cleavage also occurred in the cytosolic fraction of cells in response to anisomycin, and Bid was subsequently activated as observed by the appearance of a $14 \mathrm{kDa}$ cleavage product in the pellet fraction and a decrease in the parent band in the cytosol fraction.

A range of concentrations of zinc were administered to ML1 cells concurrently with anisomycin. Zinc at $0.1-0.3 \mathrm{mM}$ inhibited Bax translocation and, as a result, all of the subsequent steps in apoptosis that were measured (Figure 1). At $0.3 \mathrm{mM}$ zinc, cytochrome $c$ was retained in the pellet fraction and caspase 8 and Bid cleavage no longer occurred.

Parallel experiments were performed in Jurkat cells that express Bak but not Bax. All of the common steps in chemicalinduced apoptosis were activated by anisomycin (Figure 2). Zinc inhibited all the steps in Jurkat cells as it did in ML-1 cells, suggesting that the same upstream apoptotic signaling step was inhibited by zinc. Specifically, $0.3 \mathrm{mM}$ zinc inhibited DNA digestion and cleavage of D4-GDI. Cytochrome $c$ release into the cytosol, caspase 8 cleavage, and Bid activation were also inhibited at this concentration, as seen in ML-1 cells.

\section{Zinc inhibits Bax and Bak oligomerization that normally occur during anisomycin-mediated apoptosis}

We next measured the ability of zinc to inhibit Bax oligomerization in response to activation of the chemical pathway of apoptosis. ML-1 cells were incubated with anisomycin and increasing concentrations of zinc. Total lysates of these cells were then obtained by digitonin lysis. Samples were crosslinked by glutaraldehyde and Western blot analysis was performed. No crosslinking of Bax was observed in the absence of an insult (Figure 3a). Following incubation with anisomycin, Bax oligomerization was observed. We have previously shown that the size of the observed bands is consistent with homo-oligomerization. ${ }^{10}$ Although $0.3 \mathrm{mM}$ zinc inhibited cytochrome $c$ release when given in combination with anisomycin, Bax oligomer formation was only partially reduced at this concentration of zinc. This inhibition is most obvious in the reduction of intensity of the high molecular weight bands, while at $3 \mathrm{mM}$ zinc, oligomer formation was almost completely inhibited.

In ML-1 cells, Bak oligomer formation was also evident but was far less prominent than Bax oligomerization (Figure 3). It is possible that Bak is only secondarily a player in ML- 1 cells and this accounts for the low level of oligomerized Bak. However, the weak signal of Bak oligomerization was inhibited by $0.3 \mathrm{mM}$ zinc. Bak oligomerization was much more evident in Jurkat cells that lack Bax (Figure $3 b$ ). This oligomerization was substantially, but not completely, inhibited at $0.3 \mathrm{mM}$ zinc. The fact that oligomerization of Bax and Bak was not completely inhibited at concentrations of zinc that completely prevented cytochrome $c$ release is consistent with the idea that large molecular weight oligomers may be required for cytochrome $c$ release. Hence, partial block of oligomer formation may be adequate to prevent cytochrome $c$ release (see Discussion).

\section{Zinc has multiple effects on the Fas pathway}

We previously demonstrated that zinc can also prevent DNA digestion caused by receptor-mediated pathways of apoptosis. ${ }^{14} \mathrm{ML}-1$ cells do not die rapidly upon incubation with antiFas antibody; therefore, the following experiments were performed in Jurkat cells. Cells were incubated for $5 \mathrm{~h}$ with $200 \mathrm{ng} / \mathrm{ml}$ anti-Fas antibody. Fas receptor activation caused DNA digestion as measured by agarose gel electrophoresis and D4GDI cleavage indicative of caspase 3 activation (Figure 4a). In control cells, caspase 8 was found in the cytosolic fraction of cells (Figure $4 b$ ). With the activation of the Fas receptor, caspase 8 was cleaved and found in both the cytosol and pellet fractions. Bid was found in the cytosol of control cells and anti-Fas antibody caused cleavage, and translocation to the pellet fraction. Cytochrome $c$ was released into the cytosol by engagement of the Fas receptor just as in response to chemical-mediated apoptosis.

Increasing concentrations of zinc were coadministered with the anti-Fas antibody. Zinc ( $3 \mathrm{mM})$ inhibited DNA digestion and D4GDI cleavage (Figure 4a). This was 10-fold higher than the concentration required to inhibit DNA digestion induced by anisomycin. Increasing concentrations of zinc inhibited the 
a

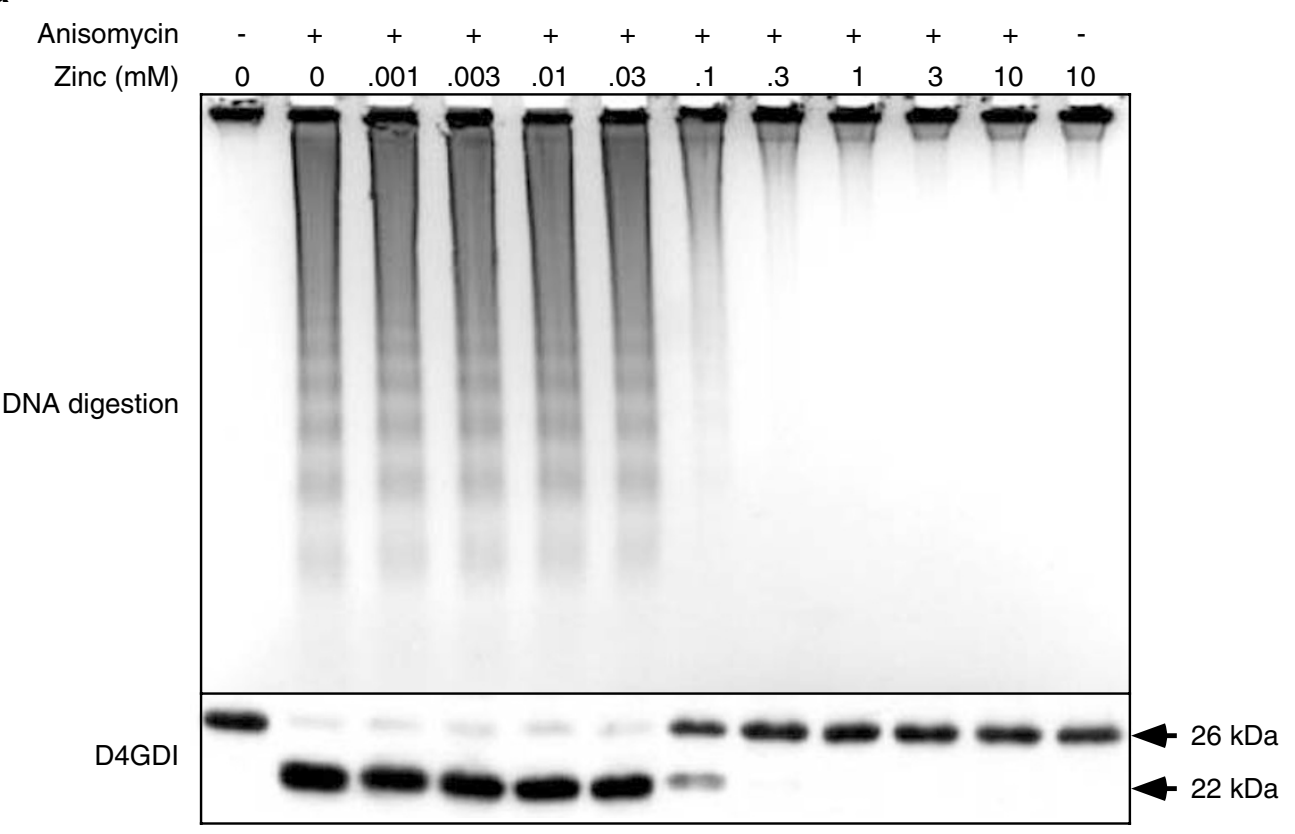

b

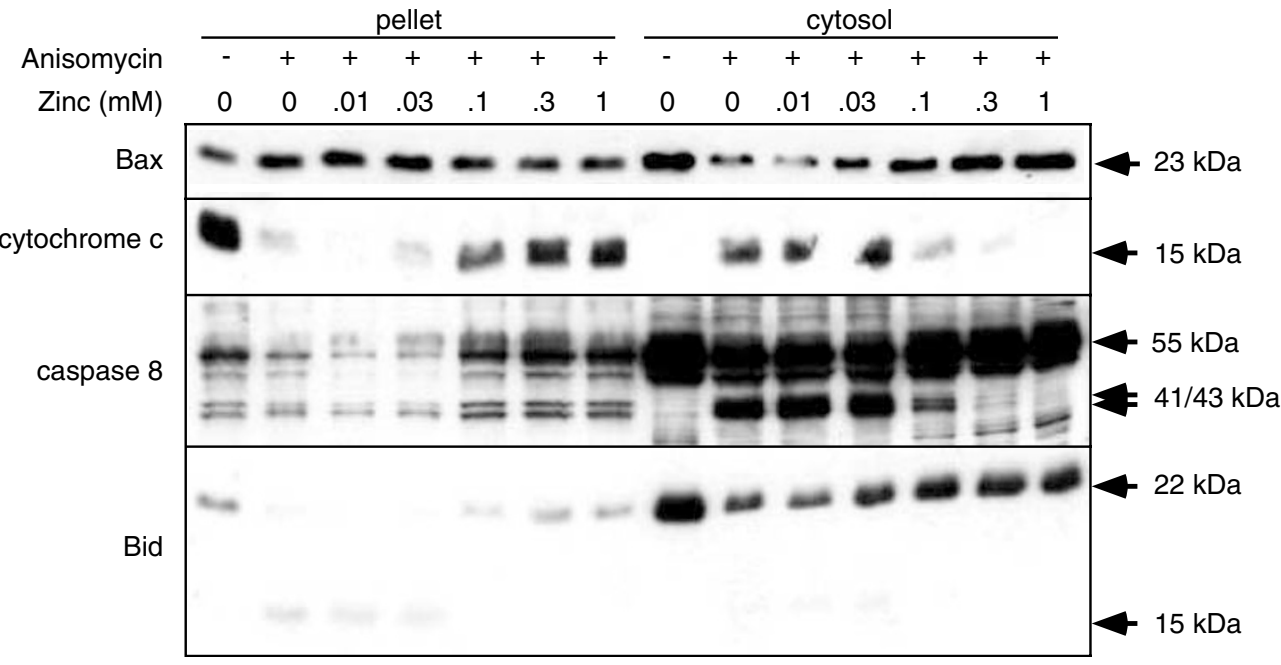

Figure 1 Zinc inhibits anisomycin-induced apoptosis in ML-1 cells. Cells were incubated with $10 \mu \mathrm{g} / \mathrm{ml}$ anisomycin and the indicated concentrations of zinc for $2 \mathrm{~h}$. (a) DNA digestion was measured by agarose gel electrophoresis, and D4GDI cleavage was measured by Western blotting of total cell lysates. (b) Cell pellet and cytosol were separated by digitonin treatment, and the fractions were assayed by Western blotting for Bax, cytochrome $c$, caspase 8 , and Bid

appearance of the cleaved product of caspase 8 in the cytosol, but had no effect on the cleavage of caspase 8 in the pellet. However, the higher concentrations of zinc resulted in accumulation of the uncleaved parent form of caspase 8 in the pellet. This is consistent with the reported mechanism by which caspase 8 is recruited to the receptor where it is cleaved and eventually released back into the cytosol. These results suggest that zinc prevents the release of cleaved caspase 8 from the DISC.

Caspase 8 was clearly active in the pellet fraction as indicated by cleavage of Bid. Furthermore, zinc appeared to stabilize the cleaved form of Bid, which is frequently difficult to see because of secondary proteolysis. Only at the highest concentration of zinc was there a reduced level of Bid, yet this was similar in amount to that seen with anti-Fas antibody in the absence of zinc and is therefore likely to be sufficient to facilitate the release of cytochrome $c$.

\section{Zinc does not inhibit Bak oligomerization that occurs during Fas-mediated apoptosis}

Bid activation by anti-Fas results in Bak activation in the same fashion as Bax to facilitate cytochrome $c$ release. ${ }^{26}$ Treatment of Jurkat cells with anti-Fas resulted in the oligomerization of Bak as measured by glutaraldehyde crosslinking of cell 
a

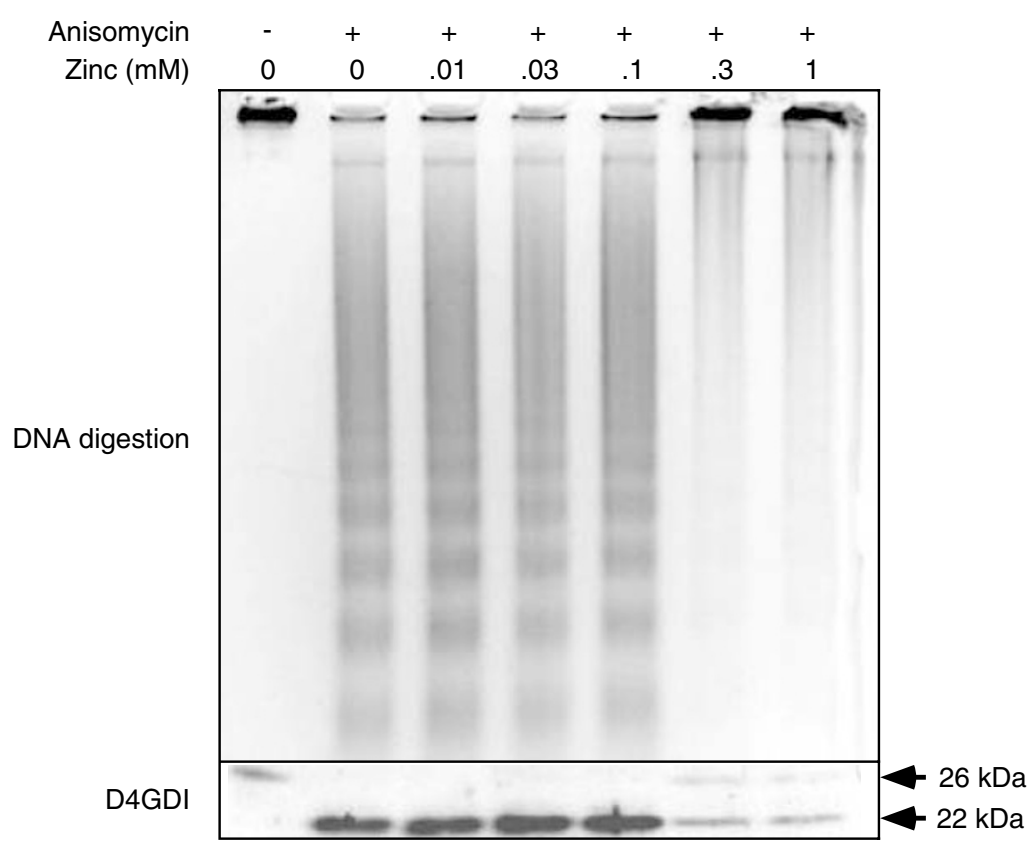

b

Figure 2 Zinc inhibits anisomycin-induced apoptosis in Jurkat cells. Cells were incubated with $10 \mu \mathrm{g} / \mathrm{ml}$ anisomycin and the indicated concentrations of zinc for $2 \mathrm{~h}$. (a) DNA digestion was measured by agarose gel electrophoresis, and D4GDI cleavage was measured by Western blotting of total cell lysates. (b) Cell pellet and cytosol were separated by digitonin treatment, and the fractions were assayed by Western blotting for Bax, cytochrome $c$, caspase 8 , and Bid

lysates, followed by Western blot analysis (Figure 5). Zinc at all concentrations used failed to prevent Bak oligomerization. This is consistent with the inability of zinc to inhibit cytochrome $c$ release from the mitochondria in response to Fas. Together these results demonstrate that, in contrast to the chemicalinduced pathway, zinc inhibits the Fas-mediated apoptosis downstream of mitochondria; that is, after release of mitochondrial cytochrome $c$ but before the proteolytic cleavage events mediated by downstream caspases.

\section{Zinc inhibits apoptosis induced by TNF plus cycloheximide}

In order to investigate the ability of zinc to inhibit receptormediated apoptosis in a cell line containing both Bak and Bax, $\mathrm{ML}-1$ cells were treated with TNF and cycloheximide $(\mathrm{CHX})$ in conjunction with increasing concentrations of zinc. TNF/CHX treatment alone resulted in caspase 8 cleavage and translocation of the cleaved product to the pellet fraction of cells. Bid was activated as visualized by the loss of the parent fraction of Bid in the cytosol although little of the cleaved fragment could be seen in the pellet. Bax translocated from the cytosol, cytochrome $c$ was released from the mitochondria, D4GDI was cleaved and DNA digested (Figure 6). When increasing concentrations of zinc were administered concurrently with TNF/CHX, 1-3 mM zinc appreciably inhibited DNA digestion and cleavage of the caspase 3 substrate D4GDI, which is similar to its efficacy in inhibiting Fas-induced apoptosis in Jurkat cells. However, unlike Jurkat cells, Bid cleavage in ML1 cells was also significantly inhibited by zinc, which suggests that the majority of Bid cleavage is likely a consequence of downstream caspase activation in this model. In the case of caspase $8,10 \mathrm{mM}$ zinc inhibited the appearance of the 
a

$\begin{array}{cccccccc}\text { ML-1 cells } & & & \\ \text { Anisomycin } & - & + & + & + & + & + & + \\ \text { Zinc }(\mathrm{mM}) & 0 & 0 & .1 & .3 & 1 & 3 & 10\end{array}$
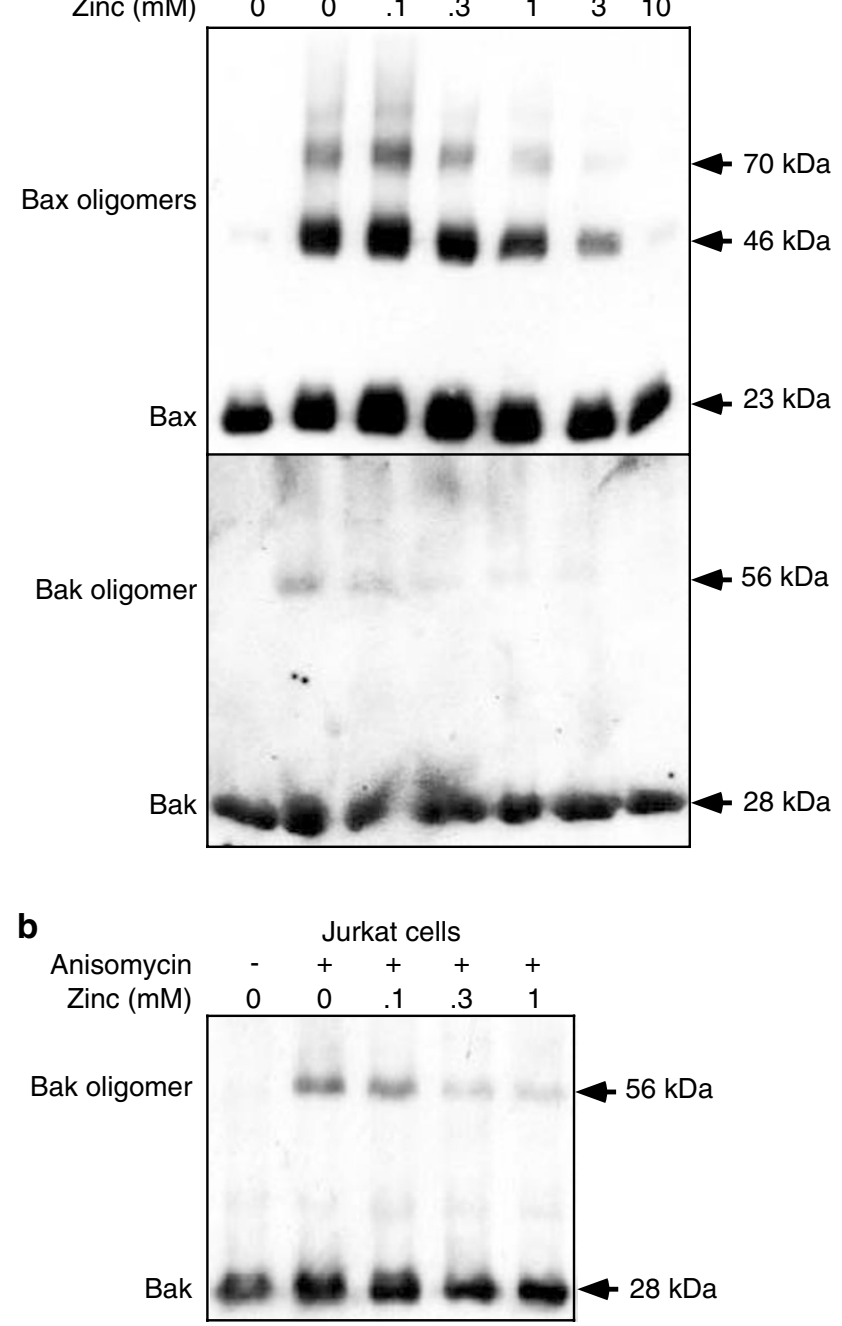

Figure 3 Bax and Bak oligomerization are induced by anisomycin and inhibited by zinc. Cells were incubated with $10 \mu \mathrm{g} / \mathrm{ml}$ anisomycin and the indicated concentrations of zinc for $2 \mathrm{~h}$. Total cell lysates were crosslinked with $0.3 \%$ glutaraldehyde and then analyzed by Western blot. (a) Bax and Bak oligomerization in ML-1 cells. (c) Bak oligomerization in Jurkat cells

cleaved fraction in the pellet, but it was still detectable in the cytosol fraction, and, furthermore, zinc did not inhibit the processing of caspase 8 from its parent form. Only partial inhibition of Bax translocation and cytochrome $c$ release was achieved at $10 \mathrm{mM}$ zinc. This result argues that Bid activation was not completely inhibited at $10 \mathrm{mM}$ zinc as enough was still present to activate Bax and Bak and result in release of cytochrome $c$. Alternately, another undefined mechanism may be facilitating Bax and Bak activation.

Bax and Bak oligomerized in response to TNF/CHX and little change was observed with zinc up to $10 \mathrm{mM}$ (Figure 7). Oligomerization, particularly in the case of Bax, generated a significant decrease in detectable antigenic epitope compared to the same samples that had not been subjected to crosslinking (note that this was also true in Figure 3 , but was not as prominent because there was a slightly lower level of overall crosslinking). This is particularly evident in the control lane in Figure 7, suggesting that unoligomerized Bax is much more susceptible to glutaraldehyde-mediated alkylation of the antibody binding site. This is probably because of the different location of Bax in the cell: soluble in control cells or mitochondrial bound in apoptotic cells. Lighter exposures of the same blot show that the total levels of Bax or Bak did not change in response to addition of either the apoptotic insult or zinc (Figure 7). In summary, these results are consistent with those obtained with anti-Fas in showing that zinc cannot prevent death-receptor-mediated Bax and Bak activation, but rather it inhibits apoptosis further downstream in the pathway.

\section{Discussion}

Zinc can inhibit apoptosis induced by both chemical and death-receptor agonists. Previous reports showed that zinc inhibits DNA digestion, caspase 3 activity, and caspase 3 activation. ${ }^{16,17,23,27,28}$ None of these reports, nor many others on the subject, defined the exact step inhibited by zinc, but rather, they suggest the inhibited step(s) are further upstream in the apoptotic cascade. In the current study, we show that the protection afforded by zinc is dependent on both the concentration of zinc and the insult employed to induce apoptosis. The most significant observation made here is that zinc can inhibit Bax and Bak activation induced by a chemical insult but not by activation of death receptors. Hence, release of cytochrome $c$ induced by anisomycin was inhibited by $\sim 0.3 \mathrm{mM}$, whereas it was not inhibited by zinc following incubation with either anti-Fas or TNF/CHX. In these deathreceptor pathways, apoptosis was still blocked by zinc, albeit at $3 \mathrm{mM}$, but this appeared to be because of inhibition of downstream caspase activity, probably because of loss of caspase activation as previously reported. ${ }^{16}$

Recent reports have shown that either Bax or Bak activation is required to induce cytochrome $c$ release in response to a chemical insult. ${ }^{5,6}$ This is consistent with our results showing that, in response to a chemical insult, ML-1 cells activate Bax and Bak, while Jurkat cells activate Bak in response to the same insult. This activation results in the release of cytochrome $c$ from the mitochondria and continuation of the apoptotic cascade. Zinc was found to inhibit Bax and Bak oligomerization that normally occurs in response to anisomycin-induced apoptosis. Although there was a clear reduction in Bax and Bak oligomerization at 0.3-1 mM zinc that correlated with inhibition of cytochrome $c$ release, complete inhibition of oligomerization was not observed until $10 \mathrm{mM}$. This finding is significant because it shows that Bax or Bak oligomerization occurs in response to an apoptotic stimulus in both pathways and that the inhibition of high molecular weight Bax or Bak oligomerization (i.e. greater than dimeric forms of Bax in Figure 3) correlates with the inhibition of cytochrome $c$ release. It has been suggested that Bax produces oligomers containing up to 30 molecules that facilitate cytochrome $c$ release, ${ }^{29}$ hence, it may not be necessary to completely block oligomerization to prevent cytochrome $c$ release. This would explain the appearance of low molecular weight oligomers of Bax or Bak, yet cytochrome $c$ was not released from the mitochondria. 


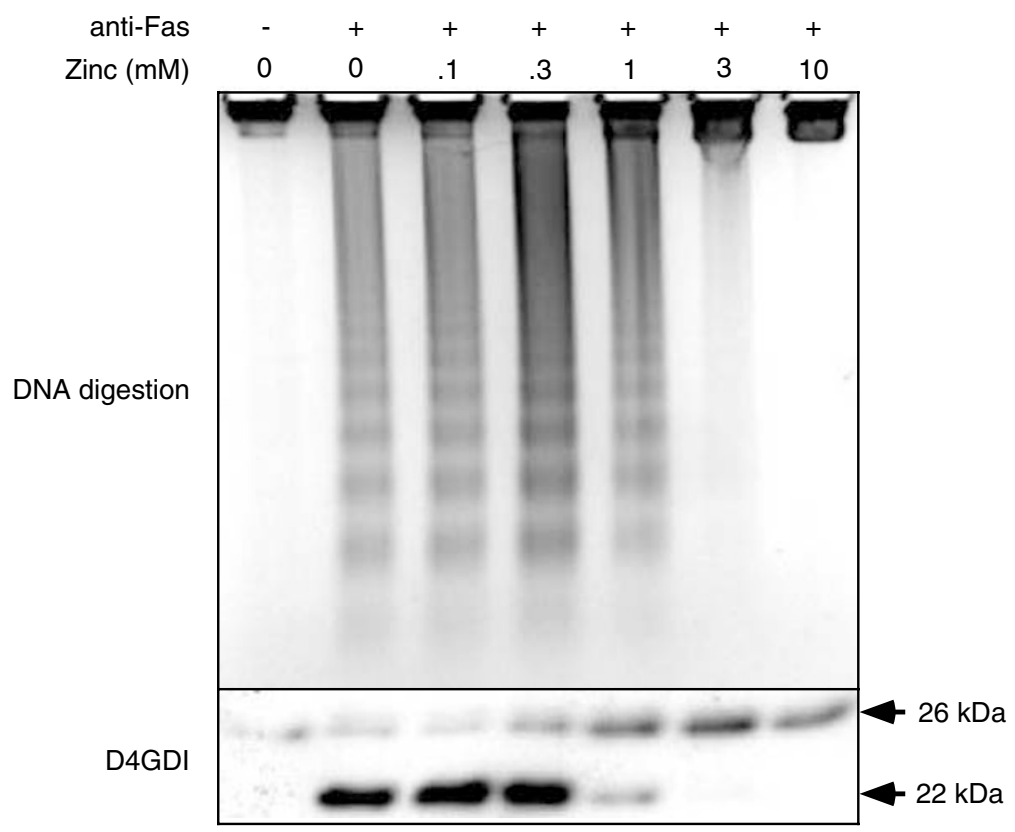

b

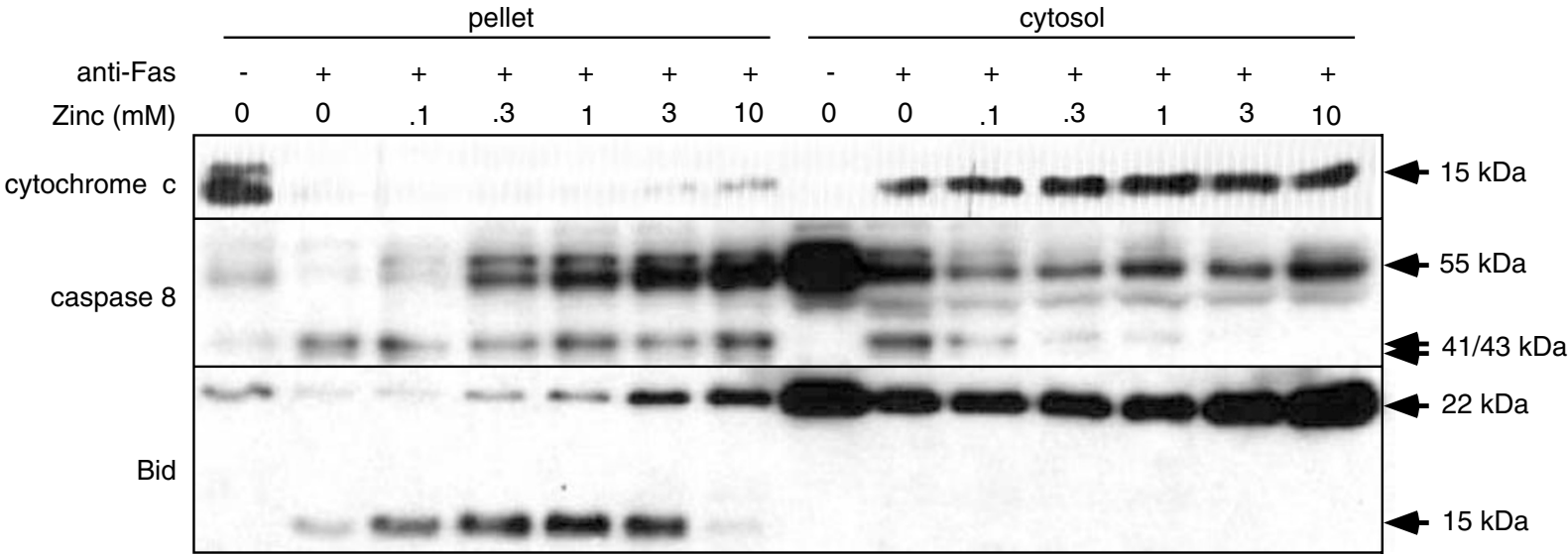

Figure 4 Zinc inhibits Fas-induced apoptosis in Jurkat cells. Cells were incubated with $200 \mathrm{ng} / \mathrm{ml}$ anti-Fas antibody and the indicated concentrations of zinc for $5 \mathrm{~h}$. (a) DNA digestion was measured by agarose gel electrophoresis, and D4GDI cleavage was measured by Western blotting of total cell lysates. (b) Cell pellet and cytosol were separated by digitonin treatment, and the fractions were assayed by Western blotting for cytochrome $c$, caspase 8 , and Bid

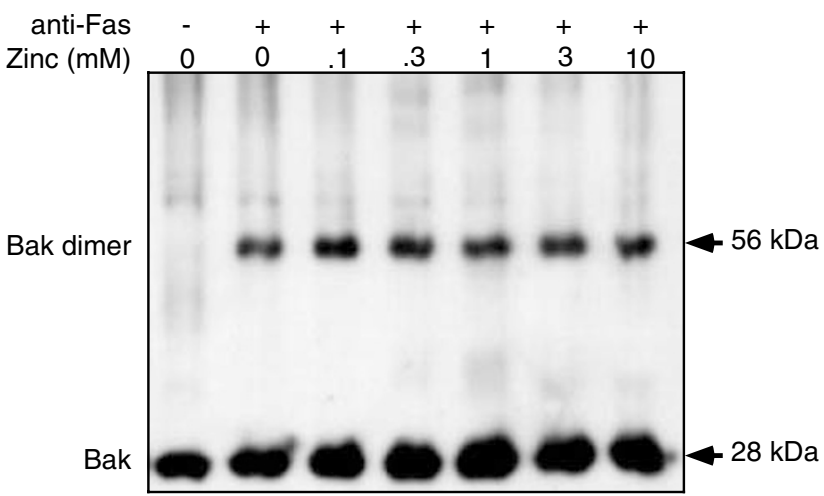

Figure 5 Bak oligomerization is induced by anti-Fas antibody but is not inhibited by zinc. Jurkat cells were incubated with $200 \mathrm{ng} / \mathrm{ml}$ anti-Fas antibody and the indicated concentrations of zinc for $5 \mathrm{~h}$. Total cell lysates were crosslinked with $0.3 \%$ glutaraldehyde and then analyzed by Western blot
Following death-receptor activation, an approximately 10-fold higher concentration of zinc was required in order to inhibit D4GDI cleavage and DNA digestion than was required to inhibit the chemical-mediated death pathway. However, zinc failed to inhibit Bax/Bak activation or cytochrome $c$ release at $3-10 \mathrm{mM}$ zinc, demonstrating that zinc must be inhibiting apoptosis downstream of these events. The ability of zinc to inhibit cleavage of D4GDI is consistent with our previous report that zinc inhibited caspase 3 activation. ${ }^{16}$ It is possible that zinc is mediating the inhibitory action at the level of the apoptosome that is required for caspase 9 activation. Alternately, in the case of a death-receptor pathway that bypasses the caspase 9 apoptosome, zinc might prevent the ability of Smac/ Diablo to activate caspase $3^{8,9}$ This downstream inhibition of the caspase cascade probably also occurs in the chemical-induced pathways but is not seen because zinc 


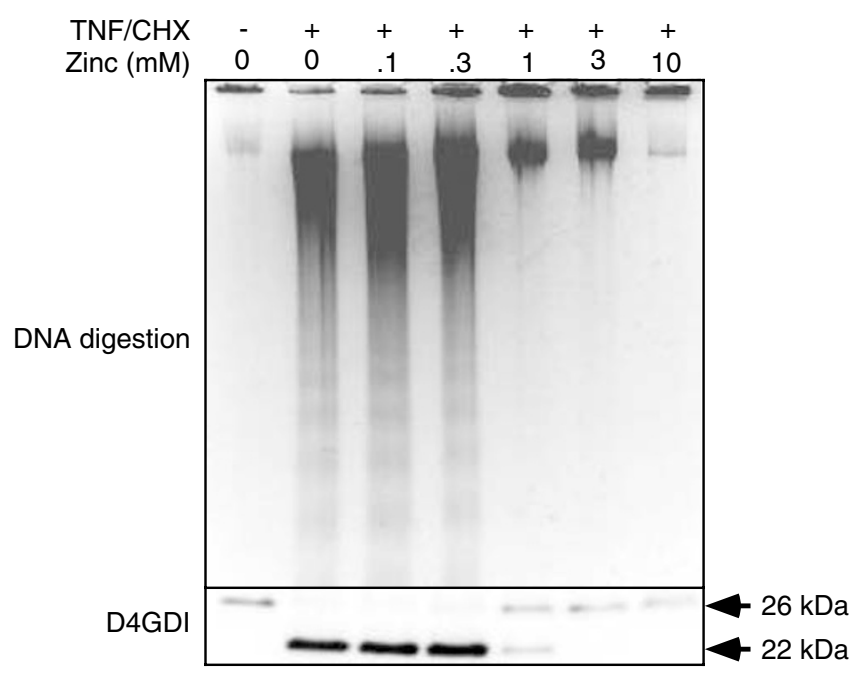

b

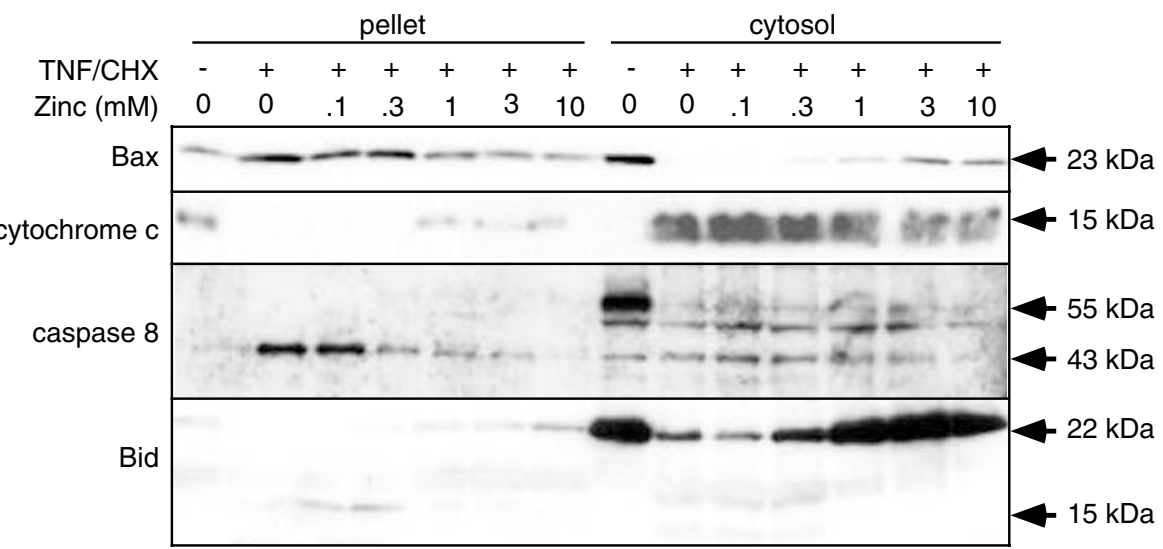

Figure 6 Zinc inhibits apoptosis induced by TNF plus cycloheximide. ML-1 cells were incubated with TNF/CHX and the indicated concentrations of zinc for $5 \mathrm{~h}$. (a) DNA digestion was measured by agarose gel electrophoresis, and D4GDI cleavage was measured by Western blotting of total cell lysates. (b) Cell pellet and cytosol were separated by digitonin treatment, and the fractions were assayed by Western blotting for Bax, cytochrome $c$, caspase 8 , and Bid

inhibits upstream of Bax and Bak activation at lower concentrations.

Zinc also caused the accumulation of full-length caspase 8 and the cleaved form of Bid in the pellet fraction when administered in conjunction with anti-Fas. We surmise that zinc may be inhibiting a secondary proteolysis of these proteins. However, accumulation of these products was not seen in TNF/CHX-mediated apoptosis. It is possible that the presence of $\mathrm{CHX}$ in this model prevents the accumulation of these products.

Caspase 8 is recruited to the Fas receptor where it is activated. This recruitment results in cleavage and activation of Bid. Bid is a proapoptotic 'BH3-only' member of the Bcl-2 family. Other $\mathrm{BH}$-only proteins have been identified and the current model suggests that different $\mathrm{BH} 3$-only proteins are triggered by different insults and that they are required for Bax and Bak activation and subsequent release of cytochrome $c .^{30}$ In the case of engagement of the death receptors, Bid is thought to be the primary $\mathrm{BH} 3-$ only protein assisting in the activation of Bax and Bak. The results presented here show that neither Bid cleavage nor Bax and Bak activation are inhibited by zinc in the death-receptor model. In contrast, in the case of anisomycin-mediated apoptosis, zinc does block Bax and Bak activation. This is consistent with previous data showing that Bid does not play a role in mediating Bax or Bak activation in response to apoptosis induced by a variety of chemical insults, ${ }^{2,10}$ and, furthemore, that Bid-deficient cells are not resistant to chemical insults. ${ }^{31}$ Presumably, a different $\mathrm{BH} 3-$ only protein is involved in mediating Bax and Bak activation in anisomycin-induced apoptosis. Several BH3only proteins, such as Noxa and Puma, are transcriptionally regulated, primarily through $\mathrm{p} 53 .{ }^{30}$ Considering that anisomycin inhibits protein synthesis at the concentrations used, it is unlikely that these proteins are contributing to Bax or Bak activation in this context. Bad is regulated by phosphorylation, which leads to its sequestration on 14-3-3 proteins and away from mitochondria. Bim and Bmf are controlled by an alternate mechanism in which they are sequestered by either microtubules in the case of Bim or actin filaments in the case of Bmf. Release and translocation occurs upon receipt of an appro- 


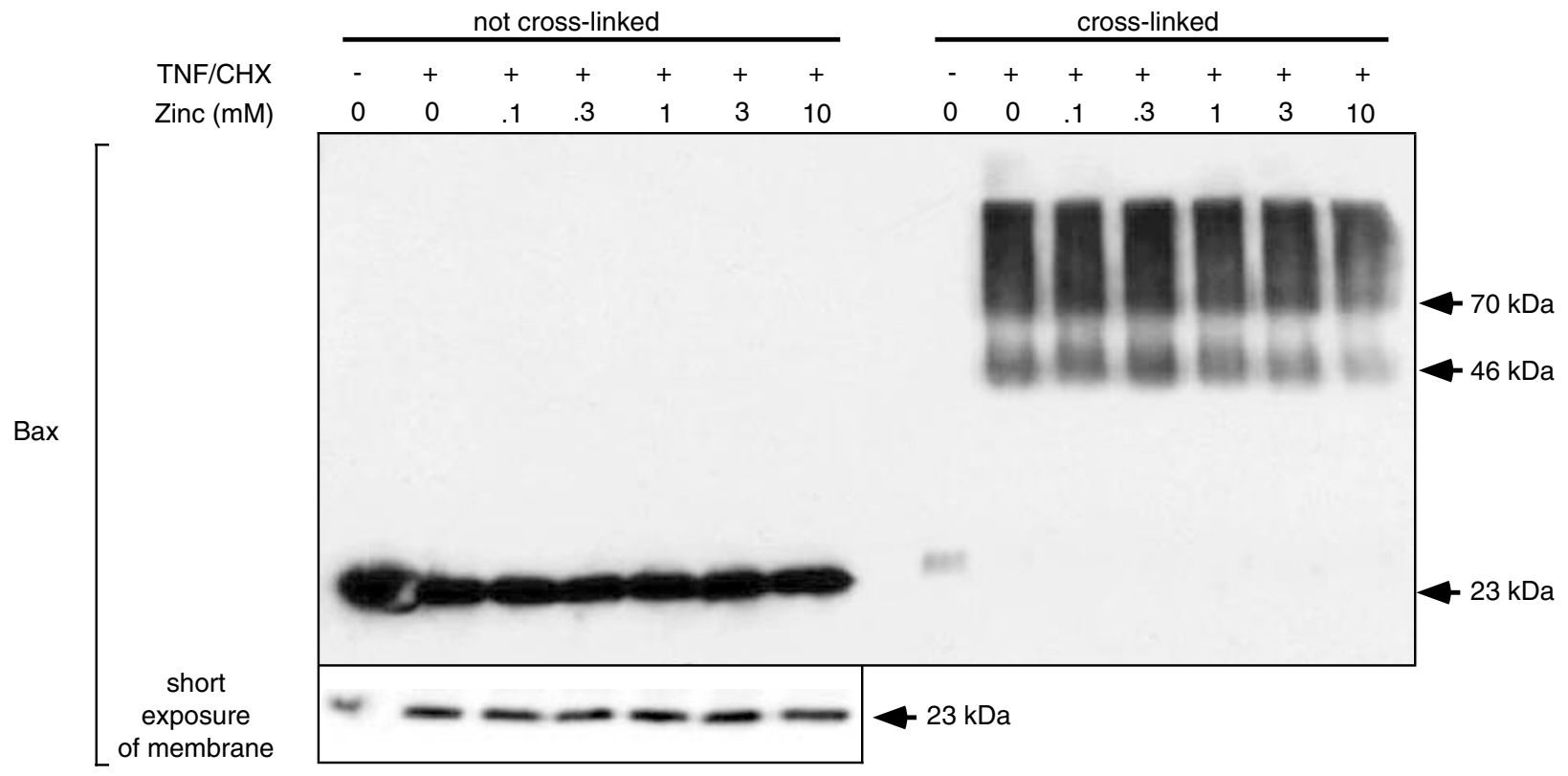

Bak $\left[\begin{array}{c}\text { short } \\ \text { exposure } \\ \text { of membrane }\end{array}\right.$

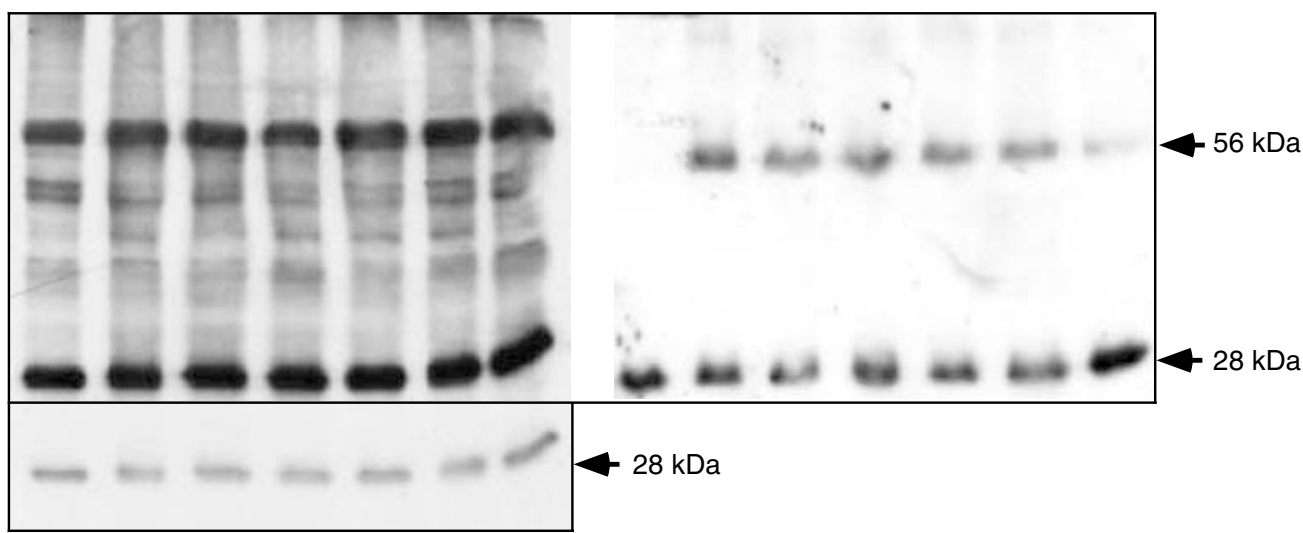

Figure 7 Bax and Bak oligomerization are induced by TNF plus cycloheximide but are not inhibited by zinc. ML-1 cells were incubated with TNF/CHX and the indicated concentrations of zinc for $5 \mathrm{~h}$. Half of the total cell lysate was crosslinked with $0.3 \%$ glutaraldehyde. Crosslinked and noncrosslinked samples were then electrophoresed on the same gel and analyzed by Western blot. In the main panels, the film was over-exposed to visualize the crosslinked bands. In the case of Bak, many additional bands are observed at this exposure in the uncrosslinked lanes, but these disappear after crosslinking; the crosslinked band is slightly smaller than the major background band and is clearly visible only after crosslinking. The lower panels show a shorter exposure of the noncrosslinked samples to demonstrate no change in the total level of Bax or Bak

priate apoptotic insult. In preliminary experiments, we have found that both Bad and Bim appear to be located primarily in the mitochondrial fraction, and in the case of Bim was completely separated from the fraction containing tubulin (data not shown). Hence, it is unlikely that Bim is sequestered by microtubules in these cell lines. One possibility is that Bim at the mitochondria is modified and/or changes conformation upon the induction of apoptosis much like Bak, and that this change allows it to bind and inhibit the antiapoptotic members of the Bcl-2 family. Alternately, Bad has recently been shown to be activated during apoptosis by phosphorylation on a novel residue, serine $128 .{ }^{32}$ Zinc could therefore inhibit apoptosis by preventing these changes. In summary, we hypothesize that zinc mediates its protection in the anisomycin model by inhibiting a particular BH3-only protein. Zinc may be a valuable tool to help resolve which $\mathrm{BH}$-only proteins are required upon induction of apoptosis by various insults.

\section{Materials and Methods}

\section{Materials}

Cell culture medium was purchased from Mediatech, Inc. (Herndon, VA, USA). All other reagents including anisomycin, zinc sulfate, and digitonin were purchased from Sigma (St. Louis, MO, USA). Monoclonal antibody to Bax was obtained from Zymed Laboratories, Inc. (San Francisco, CA, USA). Polyclonal anti-Bid was a generous gift of Dr. Xiaodong Wang (HHMI, Dallas, TX, USA). Monoclonal anti-cytochrome $c$ was purchased from Pharmingen (San Diego, CA, USA). Polyclonal anticaspase 8 was purchased from StressGen Biotechnologies Corp. (Victoria, BC, Canada). D4GDI polyclonal antibody was raised in this laboratory. ${ }^{33}$ Secondary goat anti-mouse and goat anti-rabbit antibodies conjugated with horseradish peroxidase were purchased from Bio-Rad (Hercules, CA, USA). Polyvinylidene fluoride (PVDF) membrane was from Millipore (Marlborough, MA, USA). ECL reagent was obtained from Amersham Pharmacia (Piscataway, NJ, USA). 


\section{Cell culture}

Jurkat T lymphocytes and ML-1 myeloid leukemia cells were maintained in $5 \% \mathrm{CO}_{2}$ at $37^{\circ} \mathrm{C}$ in RPMl 1640 medium complete with $7.5 \%$ fetal bovine serum and $1 \%$ glutamine. All cultures were maintained in logarithmic growth at a density less than $10^{6} \mathrm{cell} / \mathrm{s} / \mathrm{ml}$. Cells were incubated with $10 \mu \mathrm{g} /$ $\mathrm{ml}$ anisomycin for up to $2 \mathrm{~h}, 200 \mathrm{ng} / \mathrm{ml}$ anti-Fas antibody for up to $5 \mathrm{~h}$, or $10 \mathrm{ng} / \mathrm{ml}$ TNF plus $5 \mu \mathrm{g} / \mathrm{ml}$ cycloheximide for $5 \mathrm{~h}$ to induce apoptosis. Indicated concentrations of zinc were added concurrently with apoptotic agents.

\section{DNA fragmentation}

DNA digestion was measured using agarose gel electrophoresis as described previously. ${ }^{34,35}$ Briefly, $10^{6}$ cells were added directly to the wells of a $2 \%$ agarose gel, where they were lysed by SDS and digested with ribonuclease $A$ and proteinase $K$. High molecular weight DNA remained trapped in the well, while DNA that had been digested during apoptosis migrated through the gel and was resolved into multiples of 180 base pair fragments. DNA was stained with ethidium bromide and visualized under ultraviolet light.

\section{Immunoblotting}

All samples were obtained by the digitonin permeabilization method. ${ }^{36}$ Briefly, cells were permeabilized on ice with $8.75 \mu \mathrm{g}$ digitonin $/ 10^{6}$ cells in $50 \mu$ l buffer containing $75 \mathrm{mM} \mathrm{NaCl}, 1 \mathrm{mM} \mathrm{NaH}_{2} \mathrm{PO}_{4}, 8 \mathrm{mM} \mathrm{Na}_{2} \mathrm{HPO}_{4}$, $250 \mathrm{mM}$ sucrose, and protease and phosphatase inhibitors. Cells were incubated for $30 \mathrm{~s}$ on ice-cold buffer followed by centrifugation for $1 \mathrm{~min}$ at 12500 r.p.m. The supernatant was then removed as the cytosolic fraction and the pellet was resuspended in the same volume of buffer without digitonin. For total cell lysates, the same buffer was used but the fractions were not separated by centrifugation. Laemmli sample buffer $(25 \mu \mathrm{l})$ supplemented with $10 \% \quad \beta$-mercaptoethanol was then added to all samples. Total and pellet fractions were solubilized by sonicating for $5 \mathrm{~s}$ at $4^{\circ} \mathrm{C}$ and boiling for $5 \mathrm{~min}$. Extracts were electrophoresed on 15\% SDS/ polyacrylamide gels. Proteins were transferred to PVDF membrane, blocked for $1 \mathrm{~h}$ at room temperature in tris-buffered saline with $0.1 \%$ Tween 20 and $5 \%$ nonfat dairy milk. The membranes were then probed with specified antibody overnight at $4{ }^{\circ} \mathrm{C}$. Secondary antibody was used at $1: 3000$ dilution and ECL was used to detect the signal.

\section{Protein crosslinking}

Cell cytosols and pellets were isolated using digitonin lysis as described above. Cells $\left(2 \times 10^{6}\right)$ were harvested in $94 \mu$ l lysis buffer. A measure of $6 \mu \mathrm{l}$ of $5 \%$ glutaraldehyde solution was added to the final concentration of $0.3 \%$ glutaraldehyde. Samples were then incubated for $30 \mathrm{~min}$ at room temperature. After the incubation period, reactions were quenched by the addition of $25 \mu \mathrm{l}$ Laemmli sample buffer supplemented with $10 \% \beta$ mercaptoethanol. Samples were then boiled and electrophoresed on $12 \%$ SDS/polyacrylamide gels and analyzed as described above.

\section{Chromatin condensation}

Cells were incubated with $2 \mu \mathrm{g} / \mathrm{ml}$ Hoechst 33342 for $15 \mathrm{~min}$ at $37^{\circ} \mathrm{C}$. An aliquot of cells was transferred to a microscope slide, fitted with a coverslip, and DNA was visualized with a fluorescent microscope. Cells exhibiting condensed chromatin and fragmented nuclei were scored as apoptotic. At least 200 cells were scored from each sample, and data were expressed as the percentage of cells with condensed chromatin.

\section{References}

1. Martin DA, Siegel RM, Zheng L and Lenardo MJ (1988) Membrane oligomerization and cleavage activates the caspase-8 (FLICE/MACH $\alpha 1$ ) death signal. J. Biol. Chem. 273: 4345-4349

2. Sun X-M, MacFarlane M, Zhuang J, Wolf BB, Green DR and Cohen GM (1999) Distinct caspase cascades are initiated in receptor-mediated and chemicalinduced apoptosis. J. Biol. Chem. 274: 5053-5060

3. Li H, Zhu H, Xu C-J and Yuan J (1998) Cleavage of Bid by caspase 8 mediates the mitochondrial damage in the Fas pathway of apoptosis. Cell 94: 491-501

4. Lou X, Budihardjo I, Zou H, Slaughter C and Wang X (1998) Bid, a Bcl2 interacting protein, mediates cytochrome $c$ release from mitochondria in response to activation of cell surface death receptors. Cell 94: 481-490

5. Cheng EH-YA, Wei MC, Weiler S, Flavell RA, Mak TW, Lindstein T and Korsmeyer SJ (2001) BCL-2 and BCL-XL sequester BH3 domain-only molecules preventing Bax- and Bak-mediated mitochondrial apoptosis. Mol. Cell 8: 705-711

6. Zong WX, Lindsten T, Ross AJ, MacGregor GR and Thompson CB (2001) $\mathrm{BH} 3-$ only proteins that bind pro-survival Bcl-2 family members fail to induce apoptosis in the absence of Bax and Bak. Genes Dev. 15: 1481-1486

7. Liu X, Kim CN, Yang J, Jemmerson R and Wang X (1996) Induction of apoptotic program in cell-free extracts: requirement for dATP and cytochrome c. Cell 86: 147-157

8. Du C, Fang M, Li Y and Wang $X$ (2000) Smac, a mitochondrial protein that promotes cytochrome $c$-dependent caspase activation by eliminating IAP inhibition. Cell 102: 33-42

9. Verhagen AM, Ekert PG, Pakusch M, Silke J, Connolly LM, Reid GE, Moritz RL, Simpson RJ and Vaux DL (2000) Identification of Diablo, a mammalian protein that promotes apoptosis by binding to the antagonizing IAP proteins. Cell 102: 43-53

10. Ganju N and Eastman A (2002) Bcl- $X_{L}$ and calyculin A prevent translocation of Bax to mitochondria during apoptosis. Biochem. Biophys. Res. Commun. 291: 1258-1264

11. Duke RC, Chervenak R and Cohen JJ (1983) Endogenous endonucleaseinduced DNA fragmentation: an early event in cell-mediated cytolysis. Proc. Natl. Acad. Sci. USA 80: 6361-6365

12. Allington C, Sharmovsky IL, Ross GM and Riopelle RJ (2001) Zinc inhibits p75NTR-mediated apoptosis in chick neural retina. Cell Death Differ. 8: 451456

13. Inayat-Hussain SH, Cohen GM and Cain K (1999) A reappraisal of the role of $\mathrm{Zn}^{2+}$ in TGF-beta1-induced apoptosis in primary hepatocytes. Cell. Biol. Toxicol. 15: 381-387

14. Wolf CM and Eastman A (1999) The temporal relationship between protein phosphatase, mitochondrial cytochrome $c$ release and caspase activation in apoptosis. Exp. Cell Res. 247: 505-513

15. Burzio $L$ and Koide SS (1970) A functional role of polyADPr in DNA synthesis. Biochem. Biophys. Res. Commun. 40: 1013-1020

16. Wolf CM, Morana SJ and Eastman A (1997) Zinc inhibits apoptosis upstream of ICE/CED-3 proteases rather than at the level of an endonuclease. Cell Death Differ. 4: 125-129

17. Shimizu T, Kubota M, Tanizawa A, Sano H, Kasai Y, Hashimoto H, Akiyama Y and Mikawa $H$ (1990) Inhibition of both etoposide-induced DNA fragmentation and activation of poly(ADP-ribose) synthesis by zinc ion. Biochem. Biophys. Res. Commun. 169: 1172-1177

18. Takano Y, Okudaira M and Harmon BV (1993) Apoptosis induced by microtubule disrupting drugs in cultured human lymphoma cells. Inhibitory effects of phorbol ester and zinc sulphate. Pathol. Res. Pract. 189: 197-203

19. Zalewski PD, Forbes IJ and Giannakis C (1991) Physiological role for zinc in prevention of apoptosis (gene-directed death). Biochem. Int. 24: 1093-1101

20. Duffy JY, Miller CM, Rutschilling GL, Ridder GM, Clegg MS, Keen C and Daston GP (2001) A decrease in intracellular zinc levels precedes the detection of early indicators of apoptosis in HL-60 cells. Apoptosis 6: 161-172 
21. Hyun HJ, Sohn JH, Ha DW, Ahn YH, Koh JY and Yoon YH (2001) Depletion of intracellular zinc and copper with TPEN results in apoptosis of cultured human retinal pigment epithelial cells. Invest. Opthamol. Vis. Sci. 42: 460-465

22. Hyun HJ, Sohn J, Ahn YH, Shin HC, Koh JY and Yoon YH (2000) Depletion of intracellular zinc induces macromolecule synthesis- and caspase-dependent apoptosis of cultured retinal cells. Brain Res. 869: 39-48

23. Cohen JJ and Duke RC (1984) Glucorticoid activation of a calcium-dependent endonuclease in thymocyte nuclei leads to cell death. J. Immunol. 132: 38-42

24. Csermely P, Szamel M, Resch K and Somogyi J (1988) Zinc can increase the activity of protein kinase $\mathrm{C}$ and contributes to its binding to plasma membranes in T lymphocytes. J. Biol. Chem. 263: 6487-6490

25. Klein C, Sunhara RK, Hudson TY, Heyduk T and Howlett AC (2002) Zinc inhibition of cAMP signaling. J. Biol. Chem. 277: 11859-11865

26. Shimizu S, Narita M and Tsujimoto Y (1999) Bcl-2 family proteins regulate the release of apoptogenic cytochrome $c$ by the mitochondrial channel VDAC. Nature 399: 483-487

27. Perry DK, Smyth MJ, Stennicke HR, Salvesen GS, Duriez P, Poirier GG and Hannun YA (1997) Zinc is a potent inhibitor of the apoptotic protease, caspase 3. A novel target for zinc in the inhibition of apoptosis. J. Biol. Chem. 272: 18530-18533

28. Aiuchi T, Mihara S, Nakaya M, Masuda Y, Nakajo S and Nakaya K (1998) Zinc ions prevent processing of caspase-3 during apoptosis induced by geranylgeraniol in HL-60 cells. J. Biochem. 124: 300-303
29. Mikhailov V, Mikhailova M, Pulkrabek DJ, Dong Z, Venkatachalam MA and Saikumar P (2001) Bcl-2 prevents Bax oligomerization in the mitochondrial outer membrane. J. Biol. Chem. 276: 18361-18374

30. Cory S and Adams JM (2002) The Bcl-2 family: regulators of the cellular life-ordeath switch. Nature Rev. Cancer 2: 647-656

31. Yin X-M, Wang K, Gross A, Zhao Y, Zinkel S, Klocke B, Roth KA and Korsmeyer SJ (1999) Bid-deficient mice are resistant to Fas-induced hepatocellular apoptosis. Nature 400: 886-891

32. Donovan N, Becker EBE, Konishi Y and Bonni A (2002) JNK phosphorylation and activation of BAD couples the stress-activated signaling pathway to the cell death machinery. J. Biol. Chem. 277: 40944-40949

33. Krieser RJ and Eastman A (1999) Cleavage and nuclear translocation of the caspase 3 substrate Rho GDP-dissociation inhibitor, D4-GDI, during apoptosis. Cell Death Differ. 6: 412-419

34. Barry MA and Eastman A (1993) Identification of deoxyribonuclease II as an endonuclease involved in apoptosis. Arch. Biochem. Biophys. 300: 440-450

35. Eastman A (1995) Assays for DNA fragmentation, endonucleases, and intracellular $\mathrm{pH}$ and $\mathrm{Ca}^{2+}$ associated with apoptosis. Methods Cell Biol. 46: 41-55

36. Single B, Leist M and Nicotera P (1998) Simultaneous release of adenylate kinase and cytochrome $c$ in cell death. Cell Death Differ. 5: 1001-1003 